\title{
TCOM \\ Models to build capacity for African science centres and science communication: needs and assets
}

\author{
Graham J. Walker, Leapotswe Bantsi, Siphesihle Bukhosini, \\ Knowledge Chikundi, Akash Dusrath, Martin Kafeero, \\ Bhamini Kamudu Applasawmy, Kenneth Monjero Igadwa, \\ Kabelo Moswetsi, Sandile Rikhotso, Marthinus J. Schwartz and \\ Puleng Tsie
}

\begin{abstract}
Science communication is proliferating in the developing world, however, with respect to science centres, as a whole Africa is being left behind. Here 15 participants in a capacity building program are investigated using traditional needs-based and contemporary asset-based development conceptualisations. These development theories parallel deficit and participatory approaches, respectively, within science communication and demonstrate synergies between the fields. Data showed staffing, funding, governments, host institutions, and audiences are prominent needs and assets, networks are a major asset, and identified other influential factors. Analysis suggests a coordinated model involving individuals, host institutions and governments to facilitate growth of African science centres.
\end{abstract}

Keywords

DOI

Science centres and museums; Science communication in the developing world; Science communication: theory and models

https://doi.org/10.22323/2.19010205

Submitted: 22nd October 2019

Accepted: 18th December 2019

Published: 17th February 2020

Introduction

The practice of science communication is spreading globally, however, progress in Africa - while having bright spots - is lagging, particularly regarding science centres, outreach programs and informal science learning [Trautmann and Monjero, 2019]. With one third of the world's population predicted to be living in Africa by 2050, and 60 percent of the current population under 35 [UNESCO, 2020], institutions such as science centres, working alongside formal education, can play an important role building the skills and knowledge key for knowledge-based economies [Third World Academy of Sciences, 2004]. As noted by UNESCO, "the promotion of a culture of science, of technological skills for young people, in particular ... have a potentially significant impact on [African countries'] youth capacity building and employability" [UNESCO, 2020]. 
This paper shares research on an African science centre and outreach program capacity building project. First, we locate the role of science communication in development and highlight theoretical parallels between the two. We then review science communication capacity building with an emphasis on Africa and science centres, and describe Science Circus Africa as a case study. We then discuss research on a capacity building program conducted with 15 'pioneers' - current and emerging leaders, some employed in host institutions, some solely individuals - of the sector in Southern and East Africa. The research concentrates on the needs and assets for building African science centre capacity, in line with asset-based approaches to development. Finally, recommendations for science centre development in Africa are given.

Before continuing, it is acknowledged that Africa is an incredibly diverse continent, every country is unique, however for clarity and brevity the term Africa is often used to describe multiple countries in Southern and East Africa. This is not to take away from the distinctive peoples, cultures, histories and approaches to science communication in specific countries.

Science
communication
and
development -
practical and
theoretical
linkages

Science communication has a vital role to play in development [Dickson, 2004]. This is seen at the policy level, for example in South Africa's 1996 White Paper on Science and Technology [Department of Arts, Culture, Science and Technology, 1996]:

For the national system of Innovation to become effective and successful all South Africans should participate. This requires a society which understands and values science, engineering and technology and their critical role in ensuring national prosperity and a sustainable environment. This, in turn requires that SET information be disseminated as widely as possible in ways understood and appreciated by the general public. (pp. 76-77).

Similarly, the founding director of SciDev.Net and stalwart of science journalism in the developing world, David Dickson, characterised development as the application of science and technology and highlighted that "building the capacity to absorb and make use of scientific and technical knowledge must be placed at the heart of the development aid efforts" [Dickson, 2004, p. 28, italics added].

As a common context for science communication, science centres have heeded this message and highlighted science that underpins development, including aligning with the Sustainable Development Goals [SDGs United Nations, 2019]. This has occurred at all levels, from commitments by associations [Massarani, 2016] to the activities of individual centres globally [Association of Science and Technology Centers - International Science Center and Museum Day, 2019]. Science centres are positioned to play a role in the communication and implementation of the SDGs. More broadly, science communication will be indispensable for progress - effective public engagement is critical to the social change and application of science and technology that will facilitate progress on many of the SDGs.

The connections between science communication and development, however, go beyond practicalities - there are striking parallels between theoretical models and 
their evolution. The transition from deficit to dialogue to participatory/public engagement approaches is well documented in science communication [Davies and Horst, 2016; Masson, Metcalfe and Osseweijer, 2016; Trench, 2008]. While not necessarily a continuum [Davies and Horst, 2016], the transition is typified by more interactivity with publics [Trench, 2008] and, more fundamentally, an acknowledgment that publics can aid communication and science itself - or as Masson and colleagues put it, discussing Irwin [2008], "some publics are seen to bring some useful knowledge and resources to science and policymaking". Science communication has moved from thinking of publics' knowledge as the problem to 'fix', to publics being part of the solution.

This trend parallels the progression community and international development. Historically, development focussed on the needs, or problems, that hinder development, i.e. deficits. Kretzmann and McKnight [1993] highlight "this "needs" map determines how problems are to be addressed, through deficiency-oriented policies and programs" (p. 2). They go on to note the negative implications on communities (publics): people think of themselves as fundamentally deficient and hence powerless; externally facilitated solutions are fragmented rather than acknowledging wider linkages known within the community; and the perception that only outside experts have useful information and solutions. One could criticise the deficit model on the same basis.

McKnight and Kretzmann's response is to instead focus on the capacities and skills of people, groups and institutions in the community, or Asset-Based Community Development (ABCD). According to Mathie and Cunningham [2003], "ABCD rests on the principle that a recognition of strengths and assets is more likely to inspire positive action for change in a community than is an exclusive focus on needs and problems", or as Morse [2011] puts it "it shifts the conversation from thinking of citizens as objects to fix to assets to tap" (p. 10). In parallel with participatory science communication models, Morse stresses for community development "we must engage the public at a deeper level in deliberating about the choices and possibilities before us" (p. 12).

Some key elements of ABCD include shared knowledge and understandings, a focus on relationships, associations and networks, a relocation of power and decision making, and greater participation and hence buy-in by communities [Mathie and Cunningham, 2003]. The parallels to dialogue and participatory models of science communication are clear; discussions of scientists and publics creating knowledge, shifts in power, and the role of networks and diverse actors in decision making are commonly discussed in the science communication literature [cf. Masson, Metcalfe and Osseweijer, 2016]. More fundamentally, in line with shifts in power and agency, both $A B C D$ and participatory approaches start with the assumption that publics offer unique value to both the process and potential outcomes, and this value is rarely something possessed by development agencies or science communicators.

$A B C D$ 's origins illustrate further synergies between effective approaches in development and science communication. ABCD grew out of a shift from viewing development as solely economic growth to also considering social development [Green and Haines, 2015; Ssewamala et al., 2010]. Key to this broadening was the work of Sen [1999] who proposed the increase of an individual's freedom and 
capabilities as both the aim and method of development. Mirroring realisations in science communication, Sen concludes:

\begin{abstract}
The ends and means of development call for placing the perspective of freedom at the center of the stage. The people have to be seen, in this perspective, as being actively involved - given the opportunity — in shaping their own destiny, and not just as passive recipients of the fruits of cunning development programs. (p. 53)
\end{abstract}

Contemporary approaches to both science communication and development are fundamentally about individual's and/or publics' value and agency - how they can shape science or development. While this is not an exhaustive synthesis of the two fields, particularly with respect to development theory, these parallels begin to position the methods and models used in science communication as a counterpart, or perhaps subset, of development. They also suggest the two fields could benefit from more exchange and collaboration both theoretically and practically.

\section{Science communication: development and capacity building}

As an emerging discipline, especially in the developing world, a good deal of capacity building in science communication has occurred recently. The United Nations define capacity building as "the process by which individuals, organizations, institutions and societies develop abilities to perform functions, solve problems and set and achieve objectives. It needs to be addressed at three inter-related levels: individual, institutional and societal" [United Nations Economic and Social Council, 2006, p. 7].

Gibson [2001] also notes this multilevel conceptualisation and importantly frames the capacity building recipient as having ownership of objectives:

\footnotetext{
"People helping people to build skills to change their own future. Skills can be built on a number of levels, including at the level of the individual, organization, community or system." (p. 4).
}

Weiler and Ham [2002], describing a program of capacity building and environmental tour guide training - a science communication context - focus on the ultimate goal of enabling those receiving capacity building to turn into providers, stating "ultimately, the development of local know-how, and the preparation of a cadre of professionals capable of training others, represents the goal of human capacity building in a sustainable development context" (pp. 53-54).

Other critical factors for science communication capacity building include mutual commitment by both those providing and receiving, defined focus and shared goals, and understanding of the needs of those receiving training [Fog, 2004; Weiler and Ham, 2002]. Underpinning this is the context in developing countries (typically recipients of capacity building, though the two-way benefits are significant) is likely to be different to a developed country (typically the provider), so input, consultation, shared understanding and flexibility is needed from both sides - approaches need to be adapted and models that worked in one place may not in others [Lewenstein and Joubert, 2002]. Effective capacity building comes 
from partnerships and an ability to 'walk in the others shoes'. Beyond immediate stakeholders, government support and wider networks have also been highlighted as key for growth of science communication in the developing world [Barata, Caldas and Gascoigne, 2018].

Science communication capacity building in Africa typically addresses communication between researchers and publics, e.g. teaching researchers communication skills [e.g. Khanna, 2001] or better understanding researcher-led public engagement [e.g. Ndlovu, Joubert and Boshoff, 2016]. Capacity building research in science centres and similar settings is comparatively sparse, particularly outside of South Africa, and there is little published material.

Science centre capacity building in Africa
Status of science centres in Africa and other developing regions
The role of science centres and informal learning settings in science communication has been widely identified [International Council for Science, 2006; Bell et al., 2009]. In their report Building Scientific Capacity, the Third World Academy of Sciences specifically highlight science centres, especially for youth, and emphasise the need for capacity building [Third World Academy of Sciences, 2004].

As a global movement science centres have made commitments to capacity building, pledging to "expand the activities of our sector to places and communities where science centres are needed and wanted but not yet established" [Fifth Science Centre World Congress, 2008] and "encourage the establishment of science centres and museums in parts of the world where they are lacking" [Sixth Science Centre World Congress, 2011]. This congress also included a capacity building workshop for participants across Africa and a commitment to further action, which was part of the impetus for the Science Circus Africa project described below.

Many individual projects, partnerships, and science centre associations have implemented capacity building activities. As a global movement comprised of nine geographically-based associations, however, science centres have made little coordinated progress towards capacity building in Africa. A barrier is that member-based associations exist to serve their members, and emerging centres in developing countries are rarely members. Some associations do look beyond their region and membership, for example the north American quasi-global Association of Science and Technology Centres provide conference fellowships for Africans and promote global dialogue [Association of Science and Technology Centers, 2015], and the Indian National Council of Science Museums was pivotal in establishing a centre in Mauritius. Nevertheless, there is scope for increased, globally coordinated capacity building to promote growth of science centres in the developing world, especially in Africa.

Science centres have grown considerably in some countries in Africa over the past 15 years. Membership of the Southern African Association of Science and Technology Centres shows only two of the 59 members are from outside South Africa [Southern Africa Association of Science \& Technology Centres, 2019]. The North Africa and Middle East Science Centers Network lists centres in Egypt and Tunisia, however most members are in the Middle East [NAMES, 2018]. These statistics, however, do not capture smaller centres without association/network membership. 
A recent study assessing numbers of science centres in Africa concluded there were 40 centres in Africa, representing five percent of centres globally, and also highlighted South Africa's large share [Trautmann and Monjero, 2019]. They stated that in Africa:

... only 8 countries ( $15 \%$ ) have at least one science center. South Africa has 32 ( $80 \%$ of African science centers), with the rest of Africa being served by only 8 science centers $(20 \%$, some of them very small or still emerging). The vast majority of people in Africa (well over 1.1 billion) have no access to a science center. (p. 3).

In parallel to this, only one university on the continent, South Africa's Stellenbosch University, offers science communication (as opposed to journalism) at degree level [Joubert, 2018] — though a recent South African white paper proposes integrating science communication throughout tertiary science studies [Department of Science and Technology, 2018]. This has implications for the skills and knowledge of potential staff and the awareness and status of science communication careers - a profession backed up by a specialised degree has wider credibility.

The situation is contrasted by that of Latin America and the Caribbean. Initial establishment of centres in the 1990s has grown to over 470 science centres and museums as of 2015 according to RedPOP, the Latin American and Caribbean Network for the Popularization of Science and Technology, with 22 postgraduate science communication courses across five countries [Massarani et al., 2016]. The general public are also increasingly visiting science centres, with a Brazilian survey seeing growth from 4\% in 2006 to 12\% in 2015 [Barata, Caldas and Gascoigne, 2018], which is comparable to the last surveyed levels in the European Union of 16\% [European Commission, 2005].

Taken together, this suggests that the science centre sector across Africa is being left behind compared to other developing regions, underscoring a need for capacity building in the region - especially given the role that science centres can play in sustainable development as highlighted by UNESCO [Bokova, 2017].

\section{Applying asset-based approaches to science centre capacity building}

The research presented here seeks to apply asset-based approaches from development theory to inform science communication capacity building. This paper focuses on research on leaders and individuals pivotal to the development of science centres in Southern and East Africa who have been involved in Science Circus Africa capacity building programs both in Africa and Australia. The main program involves capacity building through partnership and co-delivery of real-world outreach programs; embedding training in authentic settings to maximise effectiveness [Baram-Tsabari and Lewenstein, 2017; Silva and Bultitude, 2009]. The program has reached 10 African countries and 73,300 people (mainly youth) and trained 499 people from African partner organisations, with a smaller cohort receiving in-depth training over several weeks. The program's African partners have gone on to independently run programs reaching over 200,000 people and counting, demonstrating the program is effective at building sustainable capacity. 


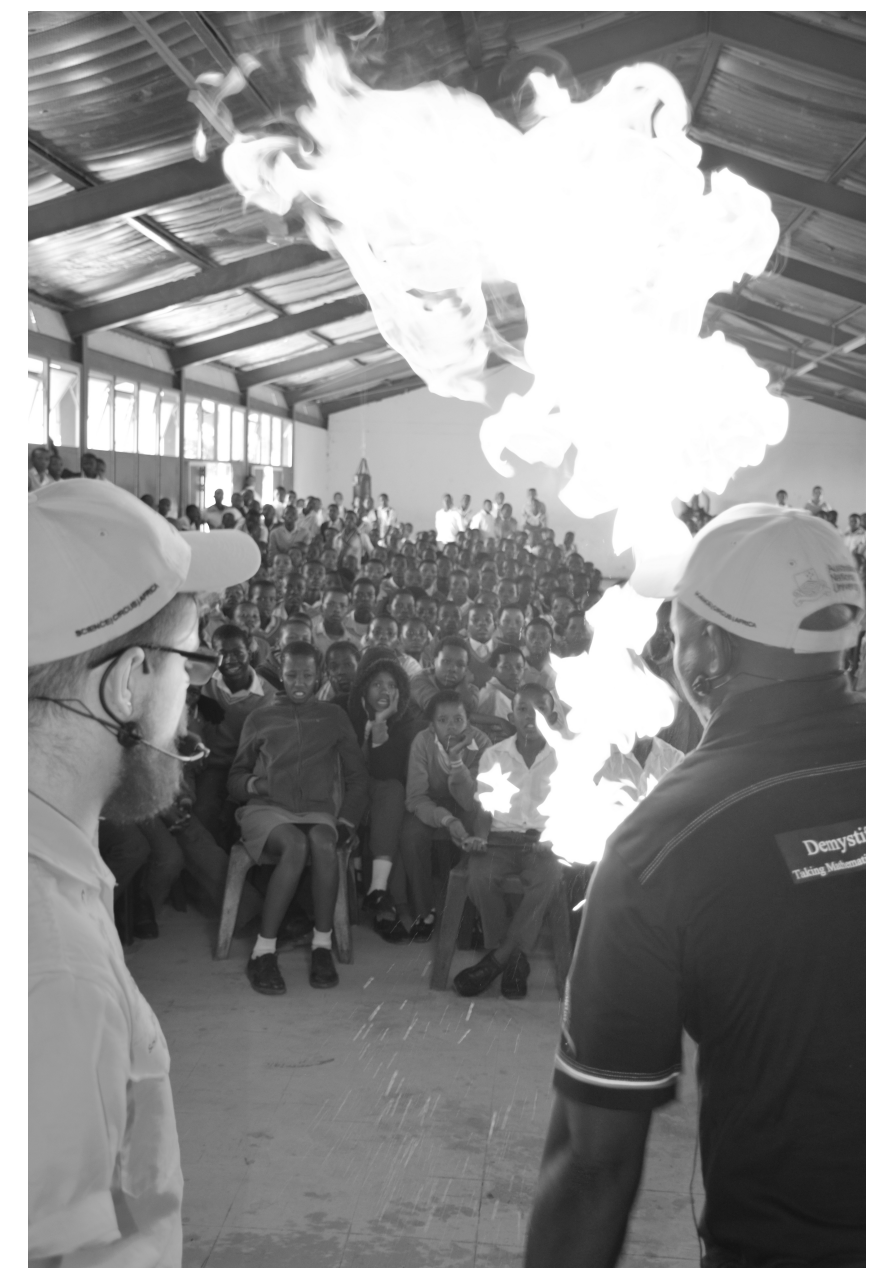

Figure 1. Presenters from Botswana and Australia co-deliver a bilingual science show in Botswana as part of the Science Circus Africa capacity building program.

\section{Methods}


remaining nine were all active in running outreach programs with aspirations to build science centres. Six were female and nine male.

The research was approved by the Australian National University Human Research Ethics Committee, protocol: 2017/107.

Survey

A survey was administered to gauge assets and needs. A survey was chosen to allow participants time to reflect on their circumstances in an environment separate to the researcher and also because of practical considerations around time available, connectivity and the geographic spread of participants. The survey included open-ended questions about the top five problems/difficulties (needs) participants faced along with the top five things that helped (assets).

\section{Analysis}

Survey responses were coded using open and axial coding [Strauss and Corbin, 1990]. Open coding establishes general emergent categories from within the data in a similar way to Grounded Theory Analysis, while axial coding establishes linkages among the emergent themes to understand the relationships among the variables. Such approaches are considered advantageous over more rigid coding approaches as they allow research findings to emerge from the data without the restraints imposed by more structured methodologies [Glaser and Strauss, 1967; Hay, 2010]. While all coding was completed by a single author (G.J.W.), to ensure that emerging themes were valid and relevant, the evolving interpretations were continually verified against the raw data from which they were derived [following previous studies, e.g. Cvitanovic et al., 2018]. Categories and descriptions were then shared with all authors for consideration, review and refinement, however, formal interrater reliability processes were not conducted due to the limited research experience of some authors. The authors' experience with capacity building and science centre programs helped inform initial categories, however new categories emerged and some required division. Many responses did not code into a discreet category and where trends were identified these highlighted linkages (i.e. axial coding; how assets were linked to other assets and similarly for needs).

\section{Results}

\section{Needs and assets categories}

Twelve categories were identified through coding (Table 1). The frequency of codes and description of categories, along with linkages, is presented below.

\section{Needs and assets - frequency, description and linkages}

Frequencies from coding are presented in Table 2. Coding revealed many categories had both asset and need dimensions and there were clear linkages between certain categories. 
Table 1. Categories of needs and assets.

\begin{tabular}{|c|c|}
\hline Category & Description \\
\hline Staffing & $\begin{array}{l}\text { Personnel involved in staffing science centres and outreach pro- } \\
\text { grams, including management staff, volunteers and interns. }\end{array}$ \\
\hline Facilities & $\begin{array}{l}\text { Buildings, workshops and infrastructure, e.g. purpose-built science } \\
\text { centres, rooms or buildings repurposed as such, university build- } \\
\text { ings, etc. }\end{array}$ \\
\hline Funding & $\begin{array}{l}\text { Cash and in-kind support required to fund programs, staff and } \\
\text { overheads, including funding sources such as grants. }\end{array}$ \\
\hline Government & $\begin{array}{l}\text { Government agencies including ministries of science and techno- } \\
\text { logy, from general bureaucrats to politicians/Ministers, but exclud- } \\
\text { ing education departments and government schools. }\end{array}$ \\
\hline Hosts & $\begin{array}{l}\text { Umbrella institutions that host science centres or outreach func- } \\
\text { tions, specifically universities, cultural museums or research insti- } \\
\text { tutions. }\end{array}$ \\
\hline Equipment & $\begin{array}{l}\text { Materials required for programs such as hands-on activities, sci- } \\
\text { ence shows, etc. including everyday items, but excluding interact- } \\
\text { ive exhibits. }\end{array}$ \\
\hline Exhibits & $\begin{array}{l}\text { Interactive science centre exhibits, but typically with lower cost } \\
\text { construction. }\end{array}$ \\
\hline Audiences & $\begin{array}{l}\text { Key audiences for programs, primarily schools, students and teach- } \\
\text { ers - including respective government departments - and asso- } \\
\text { ciated stakeholders such as parents. African science centres and } \\
\text { outreach programs have less focus on the general public compared } \\
\text { to developed nations. }\end{array}$ \\
\hline Mobility & $\begin{array}{l}\text { The ability of mainly programs but also audiences to travel, includ- } \\
\text { ing access to vehicles. }\end{array}$ \\
\hline Evaluation & $\begin{array}{l}\text { Skills, knowledge and activity in assessing programs, particularly } \\
\text { impact assessment and reporting. }\end{array}$ \\
\hline Marketing/media & $\begin{array}{l}\text { Public relations, such as preparing press releases and promotional } \\
\text { materials and engaging journalists. }\end{array}$ \\
\hline Networks & $\begin{array}{l}\text { Personal and organisational networks, within and between African } \\
\text { countries and internationally, and for larger organisations internal } \\
\text { networks. }\end{array}$ \\
\hline
\end{tabular}

The following sections describe the nature of the needs and assets based on participants' responses. Frequency is described as minor (1-4 mentions), midrange (5-9) and major (10 and above). Where coding revealed linkages between two codes, to avoid repetition, these are reported in the category where the trend was most dominant and clearly seen, e.g. in the linkage between assets of facilities and hosts, hosts were linked to a range of other categories, while with facilities the link to hosts was discrete and dominant. Nexus categories that were highly interlinked with many categories, such as funding, are also discussed.

\section{Staffing}

Needs. Staffing was the second highest major need, with participants noting a lack of staff, few training opportunities, low expertise which affected morale and enthusiasm, and limited funds for wages - with many participants highlighting the reliance on volunteers and/or self-funding. Staff retention and turnover was 
Table 2. Needs and assets coding frequencies. Linkages are shown in brackets where a link was dominant, i.e. there was a discrete link to just one other category, and/or where it was interlinked to several other categories.

\begin{tabular}{|c|c|c|}
\hline Category & Needs & Assets \\
\hline Staffing & 14 & 14 (3 Government) \\
\hline Facilities & 6 (3 Funding) & 3 (2 Hosts) \\
\hline Funding & 17 (5 Government; 7 interlinked) & 9 (7 interlinked) \\
\hline Government & 10 (5 Funds; 2 interlinked) & 10 (6 interlinked) \\
\hline Host institutions & 7 (2 interlinked) & 13 (8 interlinked) \\
\hline Equipment & 6 & 5 \\
\hline Exhibits & 6 (3 Audiences) & 1 \\
\hline Audiences & 10 (6 interlinked) & $13(4$ interlinked $)$ \\
\hline Mobility & 3 & 3 (3 interlinked) \\
\hline Evaluation & 3 (2 Funding) & 4 (3 interlinked) \\
\hline PR / media & 2 & 13 (6 interlinked) \\
\hline Networks & 2 &
\end{tabular}

problematic, and exacerbated by a lack of career pathways and science communication not being an established profession. Often leadership and management skills were lacking, and there were barriers to accessing higher-level training/qualifications. Human resource issues meant staff were reactive, juggling multiple sometimes conflicting roles, and program impact was compromised.

Assets. Staffing was the most frequently mentioned major asset, with most assets being personal qualities. Staff were passionate, committed and motivated ("love for science - keeps us going in the hard times" - South Africa). They enjoyed the team atmosphere, collegial support, and vibrant work culture. Several respondents mentioned the willingness and generosity of volunteers ("I have a team of 15 and all are volunteers. They are so enthusiastic and willing to run programs and assemble exhibits even without pay" - Kenya) and the importance of organised volunteer programs. Another common theme was government paid volunteer/internship programs (a major program in South Africa) and government support for wages - asset coding revealed a clear linkage between staff and government.

\section{Facilities}

Needs. Facilities was a midrange need (despite nine participants lacking a physical centre), though its absence limited programs/venues, had cost implications for alternative venues, and created storage and equipment maintenance problems. Large capital costs compounded by unfamiliarity with centres amongst politicians and decision makers who may fund construction were a common challenge. Coding revealed clear relationships between facilities and funding.

Assets. The benefits of a building were reported as a minor asset. Participants in host institutions such as universities, cultural museums and research organisations 
were positive about the access to facilities this entailed, and coding showed a clear link between facilities and host institutions. Participants noted that it was more than just a building; the physical presence helped establish their brand, gave a space for evolution and continual improvement, and aided logistics ("Having the available infrastructure, in terms of physical facilities, resources and previous programs, allows for programs to be run more efficiently and more effectively" — South Africa).

\section{Funding}

Needs. Funding was the most frequently noted major need, limiting equipment, staffing, facilities and programs. It was widely interlinked to needs in other categories. Reliance on government funding was a common problem, often due to bureaucratic complications and unreliability. There were few income streams, which limited scope/diversity of activities, and little private sector support. Respondents noted the lack of thorough evaluation hampered securing funds.

Assets. Funding was a midrange asset, with respondents emphasising host institution and government provided salaries, the critical need for executive support, and difficulty sourcing salaries from sponsorship or cost recovery models. Funding via grants, diplomatic missions, and corporates was highlighted - especially for operational costs and special projects. Visibility, media coverage and reputation were cited as underpinning factors. Like funding as a need, it was highly interlinked with other assets.

\section{Government}

Needs. Government was a major need, with shallow understanding of a science centre/outreach program's role a key underlying problem. This included scepticism of the educational value and confusion of the relationship to formal science education. General issues such as limited/sporadic funding, stifling bureaucracy, slow implementation and political interference were noted. While linked to other categories, there was a prominent linkage to funding needs.

Assets. Government was a major asset, particularly re support for salaries, internships, operations and programs - coding revealed strong links to funding and staff ("Without their funding support the programme would not be able to take place. From providing transportation for the learners to enabling materials for activities to be purchased for workshops and shows as well as covering salary costs for staff" - South Africa). Buy-in and endorsement was reported as important, especially amongst politicians and high-level decision makers.

\section{Hosts}

Needs. Host institution needs were midrange and similar to issues with government: problematic bureaucracy and confusion around the role and value of science centres/outreach. This negatively impacted funding and created conflicting priorities (e.g. science communication being seen solely as a public relations 
activity). One respondent noted restrictions on public access to the host institution limited engagement.

Assets. Host institutions were a major asset, equal second most mentioned, and were widely linked to other assets. High-level support and executive champions were a critical theme, especially for host institution funding. Hosts provided support services, media, marketing, facilities, buildings and especially vehicles. They also facilitated internal networks and collaboration and, in universities and research institutions, straightforward involvement of scientists - this was especially valuable as it increased ownership by hosts and provided supportive expert personnel at no cost. Mirroring the public access need, participants noted when the host was a public venue like a museum this provided a ready audience ("The museum is already a public space by its nature so the bringing in of science related exhibits allow our visitors to tour and appreciate the science displays" - Malawi). This range of support/benefits from hosts meant it was highly interlinked with other assets.

\section{Equipment}

Needs. Equipment was a midrange need, with respondents noting little equipment, lack of funding for it, and problems obtaining specialist equipment locally. A key theme was participant's limited design skills, creating reliance on existing equipment or third parties - this hampered repeat engagement with audiences as they quickly see everything.

Assets. Equipment was a midrange asset, primarily because simple, everyday materials and even waste materials could be used ("Wastes has been gold to me - most materials that are termed as not important turns out very important to me. I easily do science shows even along the road without having planned. I can use old threads, papers, balloons, sticks, nature; like insects collection, etc. to showcase science" - Kenya). Moreover, everyday materials were an asset as students and teachers could replicate activities.

\section{Exhibits}

Needs. Needs around hands-on exhibits were midrange and coding showed a clear linkage to audiences and their experience - including old/worn exhibits, maintenance problems, having too few exhibits for large groups, and ensuring safety with limited resources/expertise. Participants noted limited skills in design and manufacture.

Assets. Portability of exhibits was a minor asset, however overall exhibits were not commonly mentioned as an asset, despite being a standard feature of a science centre.

\section{Audiences}

Needs. Audiences were a top three major need/problem. Challenges included diversity of cultures/languages, low English literacy, and underprivileged groups 
(e.g. orphans and people with disabilities) being marginalised due to funding limitations. There were issues around inclusion ("People/community tend to think of the [science centre] is for the educated and science people" - South Africa), low general awareness of services, and teachers sometimes felt threatened by other educational services.

Assets. Audiences were the equal second most frequently noted major asset, primarily through strong relationships with schools and endorsement of education departments promoting access - this in-principle support facilitated practical assets including school venues, student availability and uptake of teacher professional development programs and application of ideas in the classroom. Student and teacher enthusiasm, and their ability to place science in their own cultural context, was cited as an asset ("Creativity of both teachers and learners ... they are able to localise the science programs by using local languages and use songs and dance to learn science" - Malawi).

\section{Mobility}

Needs. Mobility was a minor but significant need that emerged during the coding process, with participants noting limitations on travel by both their programs and audiences, meaning it was difficult to reach all parts of their countries, reach diverse audiences and ensure equity. Lack of vehicles and the difficulty fundraising for such capital assets was a common theme.

Assets. The mobility of programs was a minor asset, with respondents reporting travelling programs could reach those who cannot travel to a centre and were a great way to market programs. Financial support and provision of vehicles by host institutions was highly valuable.

\section{Evaluation}

Needs. A lack of evaluation skills and activity and superficial evaluation - especially around long-term impact - was reported as a minor need, though had significant consequences negatively impacting funding and support from government and host institutions.

Assets. Evaluation was not cited as an asset, perhaps due to it not being widely conducted and, if done, the lack of in-depth approaches.

\section{Media and marketing}

Needs. Media and marketing was reported as a minor need, primarily around an inability to share success stories effectively, especially to key stakeholders such as government and funders ("We do great work but many times fail to tell our success stories. Press, government, funders, the general public, etc. are too often in the dark about what we are and what we do" — South Africa). 
Assets. Media and marketing were a minor asset, with respondents noting it allowed them to reach a wider audience, increase awareness/interest and assist with sponsorship and support. Host institutions marketing departments were noted as a resource.

\section{Networks}

Needs. Networks were a minor need, however respondents did note that they sometimes felt isolated. One respondent noted that a history of corruption by NGOs in their country made fundraising especially difficult.

Assets. Networks were the equal second most frequently noted major asset, with strong links to funding and host institution benefits. Networks outside science communication provided funding and collaboration from philanthropy, industry and diplomatic channels and practicalities such as free venues and equipment - reputation was critical here. Participants also emphasised networks inside science communication which shared ideas and international best practice, staff/knowledge/resource exchange, program co-delivery, collaboration across borders, and access to capacity building, which often opened up wider networks including internationally ("Capacity building programmes like the Science Circus Africa visits - these help to expose staff to best practices and motivates them ... it provides both inspiration and excitement in staff which they then want to replicate and helps to facilitate innovative thinking" - South Africa).

This paper began by comparing models of development and science communication and drawing parallels between need/deficit and asset/participatory approaches. Synthesising these conceptually similar approaches highlighted the role of beneficiaries of development or publics involved in communication, rather than development professionals or science communicators, in achieving goals. In both conceptual models, this involved shifting or sharing power and agency with beneficiaries/publics. We then discussed capacity building, which again focusses attention on those in which capacity is being built and - consistent with asset/participatory approaches - aims to unlock value and empower people, groups and organisations. In the context of the data presented here, this points to staffing as central for development of African science centres.

An adage amongst science centre professionals is a centre is as much - probably more - the people in it, as it is a physical building. Analysis here showed staffing was a double-edged sword - both an asset and need. While staff enjoyed the work and were enthusiastic, they lacked training, training opportunities and career pathways. This same enthusiasm meant organisations benefited from volunteers, who offset a lack of funding/paid staff, however volunteers were less reliable, temporary and usually not professionally qualified. In South Africa, there was reliance on government-paid volunteer programs, whereby unemployed science graduates are placed with science centres and receive a stipend. While findings showed they are an asset to centres with meagre budgets, they are subject to similar drawbacks as unpaid volunteers: their motivation varies and they see it as a 
stepping stone to other opportunities [Edwards and Graham, 2006]. This suggests that - unless there are pathways to paid jobs and careers - volunteers are a stop-gap rather than longer-term staff capacity building.

A critical subset of staffing in any developing sector are those in leadership roles - those pioneering science centres in countries where they are not yet established. In this research that included self-funded individual pioneers (e.g. one participant converted a family run tavern into a science centre) and others who worked from within hosts (e.g. moving from a lab biotechnologist to a science communication leader, or transforming university recruitment into a dynamic hands-on outreach program). In analysing 150 stories of community development, Mathie and Cunningham [2005] found a similar role for these pioneers, highlighting:

\begin{abstract}
"What stands out in these stories is the role of particular individuals who catalyze the process of development in their communities, and the strong base of associations or social networks that are mobilized in such a process. These catalysts may ... emerge because they have had some formal education, or they have travelled or worked elsewhere and returned with new ideas." (p. 176)
\end{abstract}

Networks, education, travel and new ideas were frequently highlighted in analysis and typified the pioneers described above. Mathie and Cunningham [2005] go on to note that these pioneers stimulate pride and possibility, link with supporters, and "recognize the potential within the community" (p. 176), again linking to assets such as audiences and volunteers. This furthers parallels to ABCD argued earlier and suggests the role of pioneers is key for development of science communication in Africa.

The program described here sought to build capacity in these pioneers, however definitions of capacity building stress multilevel aspects; beyond individuals. Hence, two categories that warrant further investigation are government and hosts, who provide capacity at the organisation-level. They were frequently mentioned needs and assets, however, with government the balance was even, while with hosts it was clearly weighted towards being an asset. Unpacking this relationship is revealing.

Looking at needs, with government, coding revealed a strong relationship between the funding they provide and additional challenges that creates - there is much needed support but with strings attached. While data showed similar issues for university hosts, the problems were not so evident. That is not to discount the key role government plays via policy, funding and establishing science communication departments. This was critical to rapid growth in Brazil [Barata, Caldas and Gascoigne, 2018] and South Africa [Du Plessis, 2008], with recent government accreditation programs and capacity building in the latter further assisting. The data, however, does suggest that streamlining government processes may assist science centres to grow.

Turning to assets, both government and hosts were key for providing staff and funding, and in both cases having high-level political/executive champions was crucial. Hosts, however, also brought added benefits of facilities, networks, media 
support and mobility/vehicles. Ronen Mir, discussing Ethiopian science centre capacity building, made similar observations, recommending "partner[ing] with a top-notch local university that provides a building, staff, and resources" [Association of Science and Technology Centers, 2015]. Analysis also revealed that, while challenging, on balance there was greater understanding of the role/value of centres in hosts as compared to government. This is understandable given hosts and centres have a close structural and strategic relationship. Conversely, centres' relationships with politicians and the underlying bureaucracy is more removed and variable due to policy focus, election cycles and changes of political representatives. While this suggests that hosts may be a better environment to nurture science centre development, one must note that in the African context (and many others) the largest funder of hosts is the government.

Taken together, this positions hosts as a key intermediary - they mitigate some of the disadvantages that come with government support, while adding practical benefits and facilitating closer, more integrated relationships. Moreover, the data highlight a role for cultural museums as they are already public facing organisations, while universities - while not public facing - bring unique benefits especially a scientific culture and scientists.

Critically, hosts provide opportunities and resources for the pioneers within them, again a feature observed in development studies. Extending Sen's [1999] work on development as an increase of individual freedom, Stewart [2013] argued that social institutions (hosts) affect individual's capabilities and freedoms, and hence are pivotal for development. This is illustrated in the data presented here, e.g. pioneers based within hosts can access vehicle assets, while in those without hosts it is a pressing need. Clearly hosts area central part of developing science centres in Africa.

Conclusion and implications
The findings presented here reflect the lived experience of pioneers of the science centre movement in Southern and East Africa, and hence an incredibly valuable perspective to inform recommendations for growth. The conceptual frame presented here, focussing on asset-based and participatory approaches and shifting power and agency, is also useful for framing these recommendations. Based on this, a three-tiered model based on pioneers situated at hosts within a constructive government environment emerges:

1. Empowerment of pioneers, and those they lead - pioneers are best placed to take African science centres forward. Analysis suggests they should pursue growth opportunities for staff and volunteers to foster career development, formalise volunteer programs, develop high-level relationships with champions within government and host institutions, and focus on developing capabilities that promote freedom and agency such as content creation, fundraising, evaluation and research (it is noted the lead author of this paper is not African and in some ways that is problematic; [cf. Ninnes, 1996]). Networks, leadership programs, mentoring and other ways to empower pioneers and let others emerge should be advanced - including via international collaboration - and these will thrive when based on asset-based approaches that promote pioneer's agency, innovation and goals. 
2. Host institutions - analysis here shows umbrella organisations play a key role in sustainability, growth and impact of African science centres. Universities, research institutes and museums are all effective hosts and bring different advantages. Broadening and deepening relationships with potential hosts will be a major asset for pioneers, and vice versa, and for those already within organisations nurturing relationships will bear fruit - including leveraging host capabilities (facilities, vehicles, etc.) and in stakeholder engagement, particularly as an intermediary to government. Establishing shared value and articulating the role of centres and the benefits they bring to hosts will be an asset to both pioneers and hosts.

3. Government - the above recommendations will flourish in a constructive policy context. Developing science communication policy, funding structures and dedicated departments, as has underpinned South Africa and Brazil's rapid growth, is critical. The value of centres will be enhanced when they are mindful of country contexts and government perspectives, while shared awareness across associated departments (science, education, culture, etc.) will allow centres to fully integrate with the machinery of government. Policy implementation needs to be mindful not to create additional needs as it fosters assets for the sector.

These recommendations, based on the insights of those developing the sector, focus on steps that can be taken within individual African countries or bolstered through regional collaboration, in line with the ethos of capacity building and ABCD. Nevertheless, international collaboration corresponding to the above recommendations - people to people, host to host, and government to government - can complement, and science centre networks and science peak bodies can play an important coordination role. International collaboration will be most effective when it focusses on capacity building, supports African agency, involves ongoing relationships rather than one-off projects, and wherever possible co-develops goals, content and methodologies to enhance - and be led by - African ingenuity.

As the African proverb says, "if you want to go fast, go alone; but if you want to go far, go together". This paper hopes to encourage and inform more collaboration and activity both within Africa and internationally to develop African science centres and empower them to play an even greater role in science communication and the continent's development.

Acknowledgments Thank you to all participants in the research for their enthusiasm and determination, which has energised Science Circus Africa on program and personal levels. We would also like to acknowledge the program's champions and pioneers: Mike Gore, Sue Stockylmayer, Joan Leach, Graham Durant, and support from the Australian Government. The authors are grateful to Sujatha Raman and Chris Cvitanovic, along with anonymous reviewers, for constructive comments on earlier drafts of this paper. 
Association of Science and Technology Centers (18th October 2015). Emerging science centers in Africa: learning as a field, four years after Cape Town.

URL: https://www.astc.org/annual-conference/emerging-science-centers -in-africa-learning-as-a-field-four-years-after-cape-town/.

Association of Science and Technology Centers - International Science Center and Museum Day (2019). Addressing the SDGs in Science Centers.

URL: http://www. iscsmd.org/sdgs-in-science-centers/.

Baram-Tsabari, A. and Lewenstein, B. V. (2017). 'Science communication training: what are we trying to teach?' International Journal of Science Education, Part B 7 (3), pp. 285-300. https://doi .org/10.1080/21548455.2017.1303756.

Barata, G., Caldas, G. and Gascoigne, T. (2018). 'Brazilian science communication research: national and international contributions'. Anais da Academia Brasileira de Ciências 90 (2 suppl.1), pp. 2523-2542. https://doi.org/10.1590/0001-3765201720160822.

Bell, P., Lewenstein, B., Shouse, A. W. and Feder, M. A. (2009). Learning science in informal environments: people, places and pursuits. Washington, DC, U.S.A.: The National Academies Press. https://doi .org/10.17226/12190.

Bokova, I. (21st May 2017). Message from Ms Irina Bokova, director-general of UNESCO, on the occasion of the world day for cultural diversity for dialogue and development.

URL: http://unesdoc . unesco.org/images/0024/002482/248268E.pdf.

Cvitanovic, C., Löf, M. F., Norström, A. V. and Reed, M. S. (2018). 'Building university-based boundary organisations that facilitate impacts on environmental policy and practice'. PLOS ONE 13 (9), e0203752. https://doi.org/10.1371/journal.pone.0203752.

Davies, S. R. and Horst, M. (2016). Science Communication: culture, identity and citizenship. London, New York and Shanghai: Palgrave Macmillan. https://doi.org/10.1057/978-1-137-50366-4.

Department of Arts, Culture, Science and Technology (1996). White paper on science and technology. Pretoria, South Africa.

URL: http://www.gov.za/documents/science-and-technology-white-paper.

Department of Science and Technology (2018). White paper on science, technology and innovation. URL: https://www.gov.za/sites/default/files/gcis_document/2 01809/41909gon954.pdf.

Dickson, D. (2004). 'Science and technology communication for development'. PLoS Biology 2 (1), e11. https://doi .org/10.1371/journal .pbio. 0020011.

Du Plessis, H. (2008). 'Public communication of science and technology in developing countries'. In: Handbook of Public Communication of Science and Technology. Ed. by M. Bucchi and B. Trench. London, U.K. and New York, U.S.A.: Routledge, pp. 213-223.

Edwards, D. and Graham, M. (2006). 'Museum volunteers: a discussion of challenges facing managers in the cultural and heritage sectors'. Australian Journal on Volunteering 11, pp. 19-27.

European Commission (2005). Special Eurobarometer 224: Europeans, science and technology.

Fifth Science Centre World Congress (2008). The Toronto declaration.

Fog, L. (15th February 2004). Capacity building "key to successful collaboration".

URL: https://www.scidev . net/global/news/capacity-building-key-to-suc cessful-collaboration.html (visited on 15th January 2019). 
Gibson, G. (2001). Building partnerships: key elements of capacity building an exploration of experiences with mining communities in Latin America. [MMSD working paper no. 33]. Mining, Minerals and Sustainable Development (MMSD). URL: http://pubs.iied.org/pdfs/G00538.pdf.

Glaser, B. and Strauss, A. L. (1967). The discovery of grounded theory: strategies for qualitative research. Chicago, IL, U.S.A.: Aldine.

Green, G. P. and Haines, A. (2015). Asset building \& community development. 4th ed. Washington, DC, U.S.A.: SAGE Publications.

Hay, I. (2010). Qualitative research methods in human geography. Toronto, ON, Canada: Oxford University Press.

International Council for Science (2006). Priority area assessment on capacity building in science.

Irwin, A. (2008). 'Risk, science and public communication: Third-order thinking about scientific culture'. In: Handbook of Public Communication of Science and Technology. Ed. by M. Bucchi and B. Trench. London, U.K. and New York, U.S.A.: Routledge, pp. 199-212.

Joubert, M. (2018). Personal communication.

Khanna, J. (2001). 'Science Communication in Developing Countries: Experience from WHO Workshops'. Science Communication 23 (1), pp. 50-56. https://doi.org/10.1177/1075547001023001005.

Kretzmann, J. and McKnight, J. (1993). Building communities from the inside out. Evanston, IL, U.S.A.: Institute for Policy Research.

Lewenstein, B. V. and Joubert, M. (8th-9th December 2002). Achieving public understanding of research in developing countries. Cape Town, South Africa.

Massarani, L. (15th November 2016). Science museums and UNESCO join to meet SDGs. URL: https://www.scidev.net/asia-pacific/education/scidev-netat-large/science-museums-unesco-sdgs-1.html (visited on 12th February 2019).

Massarani, L., Reynoso-Haynes, E., Murriello, S. and Castillo, A. (2016). 'Science communication postgraduate studies in Latin America: a map and some food for thought'. JCOM 15 (05), A03.

URL: https://jcom.sissa.it/archive/15/05/JC0M_1505_2016_A03.

Masson, A.-L., Metcalfe, J. and Osseweijer, P. (2016). 'Motivating engagement'. In: Science and technology education and communication: seeking synergy. Ed. by M. van der Sanden and M. J. de Vries. Rotterdam, The Netherlands: Sense Publishers, pp. 47-66. https://doi.org/10.1007/978-94-6300-738-2_4.

Mathie, A. and Cunningham, G. (2003). 'From clients to citizens: asset-based community development as a strategy for community-driven development'. Development in Practice 13 (5), pp. 474-486. https://doi.org/10.1080/0961452032000125857.

- (2005). 'Who is driving development? Reflections on the transformative potential of asset-based community development'. Canadian Journal of Development Studies/Revue canadienne d'études du développement 26 (1), pp. 175-186. https://doi.org/10.1080/02255189.2005.9669031.

Morse, S. (2011). 'Communities revisited: the best ideas of the last hundred years'. National Civic Review 100 (1), pp. 8-13. https : //doi.org/10.1002/ncr. 20042.

NAMES (2018). Full members index at www.namesnetwork.org. URL: http://www . namesnetwork. org/en/Members/Index.aspx?cat=full (visited on 12th January 2018). 
Ndlovu, H., Joubert, M. and Boshoff, N. (2016). 'Public science communication in Africa: views and practices of academics at the National University of Science and Technology in Zimbabwe'. JCOM 15 (06), A05.

URL: https://jcom.sissa.it/archive/15/06/JC0M_1506_2016_A05.

Ninnes, P. M. (1996). Informal learning strategies in the Solomon Islands. Adelaide, SA, Australia: Department of Educational and Professional Studies, School of Education, Flinders University, pp. 1-16.

Sen, A. (1999). Development as freedom. New York, NY, U.S.A.: Anchor Books.

Silva, J. and Bultitude, K. (2009). 'Best practice in communications training for public engagement with science, technology, engineering and mathematics'. JCOM 08 (02), A03.

URL: https://jcom. sissa.it/archive/08/02/Jcom0802\%282009\%29A03.

Sixth Science Centre World Congress (2011). Cape Town declaration.

Southern Africa Association of Science \& Technology Centres (2019). SAASTEC network members. URL: https://saastec.co.za/48-2/ (visited on 13th August 2019).

Ssewamala, F. M., Sperber, E., Zimmerman, J. M. and Karimli, L. (2010). 'The potential of asset-based development strategies for poverty alleviation in Sub-Saharan Africa'. International Journal of Social Welfare 19 (4), pp. 433-443. https://doi.org/10.1111/j.1468-2397.2010.00738.x.

Stewart, F. (2013). Capabilities and human development: beyond the individual - the critical role of social institutions and social competencies. Human Development Reports — UNDP 03. New York, NY, U.S.A.: United Nations Development Programme, pp. 1-20.

URL: http://hdr. undp.org/sites/default/files/hdro_1303_stewart.pdf.

Strauss, A. and Corbin, J. M. (1990). Basics of qualitative research: Grounded theory procedures and techniques. Thousand Oaks, CA, U.S.A.: Sage.

Third World Academy of Sciences (2004). Building scientific capacity: a TWAS perspective.

URL: http://twas.org/sites/default/files/capbuildreport.pdf.

Trautmann, C. and Monjero, K. (2019). 'Science centers in Africa'. Informal Learning Review 154 (January/February), pp. 3-10.

Trench, B. (2008). 'Towards an analytical framework of science communication models'. In: Communicating science in social contexts. Dordrecht, The Netherlands: Springer, pp. 119-135.

https://doi.org/10.1007/978-1-4020-8598-7_7.

UNESCO (2020). Africa department - demographic growth.

URL: http://www . unesco.org/new/en/testing/africa-relaunch/priority-a frica/operational-strategy/demographic-growth/ (visited on 28th January 2020).

United Nations (2019). Sustainable development goals.

URL: https://sustainabledevelopment.un.org/sdgs (visited on 13th August 2019).

United Nations Economic and Social Council (2006). Definition of basic concepts and terminologies in governance and public administration.

URL: https://digitallibrary . un .org/record/566603.

Weiler, B. and Ham, S. H. (2002). 'Tour guide training: a model for sustainable capacity building in developing countries'. Journal of Sustainable Tourism 10 (1), pp. 52-69. https://doi.org/10.1080/09669580208667152. 
Graham J. Walker. Graham's current research and engagement investigates international capacity building and co-design in science communication. To this end, he founded the Science Circus Africa project which has trained 499 staff and reached 73,000 people in 10 countries. He is currently developing Science Circus Pacific. Graham also researches psychological aspects of science communication, particularly in settings like science centres, science shows and hands-on workshops, and using these methods to engage with social and environmental issues. He also teaches in these areas. E-mail: g.walker@anu.edu.au.

Leapotswe Bantsi. Leapotswe is currently involved with the "engagement for development" programs of the Botswana International University of Science and Technology (BIUST) which include science circuses, STEM festivals, mentorship of pre-tertiary learners and others. While coordinating these programs, her other major interest is demonstrating the relevance of Inquiry Based Science Education as a necessary imperative for a country that aims to transit from a resource-based to knowledge-based economy. Leapotswe is working to establish Botswana's first science centre. E-mail: bantsil@biust.ac.bw.

Siphesihle Bukhosini. Siphesihle is a scientist with a passion for science communication to both the old and the young with a focus on making scientific research accessible to all. Through strategic planning and development as well as keen understanding of science, Siphesihle has mentored more than 10 individuals in the field of science communication, promoted development and growth of two science centres in remote South Africa, whilst impacting the lives of the community. E-mail: Siphesihlebukh@gmail.com.

Knowledge Chikundi. Knowledge Chikundi is the founder Africa Science Buskers Festival, which is Africa's only international science communication platform for primary and high school students and teachers. The Africa Science Buskers Festival was inspired by the impact of Science Circus Africa in Zimbabwe. He is also Director of the Zimbabwe Science Fair, an educational platform that offers Zimbabwe's passionate young scientists and innovators the opportunity to learn, connect and solve humanity's grand challenges. He regularly leads student delegations to international competitions. E-mail: knowledge@sciencebuskers.org.

Akash Dusrath. Akash currently manages the Cape Town Science Centre overseeing the organization's operations and activities. He has a decade of experience in science communication having worked in three science centres in South Africa promoting both learner and public understanding of STEM through interactive and engaging hands-on workshops, science shows, exhibits and events. He serves as the Deputy Chairman of the Southern African Association of Science and Technology Centres (SAASTEC) and is a member on the Accreditation Committee for the South African Network of Science Centres. E-mail: akashdusrath@gmail.com. 
Martin Kafeero. Martin is a science communicator from Uganda, where he is well known through TV and other mediums as a funny and engaging science performer. Over his working experience of seven years in the field, Martin has been involved in the development of science outreach programs and other initiatives in Tanzania and Uganda. He has reached out to more than 200,000 youth and children with hands-on activities through school science shows, science festivals, theatre shows, television, print media and non-science events.

E-mail: martin.martinka2018@gmail.com.

Bhamini Kamudu Applasawmy. Bhamini specializes in development and implementation of science communication programs such as science shows, competitions and teacher training workshops. She has championed several projects including the YMPP which teaches students to address the Sustainable Development Goals from a strategic planning perspective. The program won national and international awards in Quality Circles Conventions for innovation in delivery. She is a recipient of the Australian Award Fellowship in science communication. Her research area is interest and learning in informal science learning environments. E-mail: kamudu.rgsc@gmail.com.

Kenneth Monjero Igadwa. Kenneth Monjero is a research assistant at the Kenya Agricultural and Livestock Research Organization, where he works on biotechnology tools, vaccines, viruses and crop research. He is also the pioneer and founder of Science Centre Kenya, where he practices science communication. He is a global fellow for food security with academic credentials from Kenya Methodist University, University of Nairobi, Stellenbosch University, Cornell University, North West University and Australia National University. Monjero's passion is children, youth and public STEM communication. E-mail: kentrizakari@gmail.com.

Kabelo Moswetsi. Kabelo 'Nick' Moswetsi is working as Chief Coordinator - Programmes Development in the Directorate of Pre-University Academic Programmes, Botswana International University of Science and Technology (BIUST). In addition to developing outreach and engagement programs he also organises outreach activities like STEM festivals, science circuses and National Science Week. He is a master teacher of physics with many years of teaching in Botswana Secondary Schools. He has also served as a Principal Education Officer for science in the Ministry of Education Botswana. E-mail: moswetsik@biust.ac.bw.

Sandile Rikhotso. Sandile Rikhotso is Lab Technician and program coordinator at University of Limpopo Science Centre. He's been developing, managing and coordinating science communication program and projects for 13 years to date. He assists in the development of a science communication qualification at the university and also assists in the management of the science centre. He is a post-graduate marketing student; his research area of interest is science centre marketing. E-mail: Sandilebuwazi85@gmail.com. 
Marthinus J. Schwartz. MJ Schwartz is the Education Manager for the Cape Town Science Centre. He has 10 years' experience working in science communication and informal education. He holds a BSc in physics and chemistry, an honours degree in physics, a short course qualification in science communication, an Australia Awards Fellowship in science centre management and is completing his Master (astronomy) through the University of Cape (part-time). He is currently involved in a pan-African project focusing on educational conservation in several African countries. E-mail: mj.scienceguy@gmail.com.

Puleng Tsie. Puleng Tsie is an environmentalist turned science communicator. She's currently the Manager of Sci-Enza, the science centre of the University of Pretoria. She is a recipient of the Australian Award Fellowship in Science Communication and a former South African Association of Science and Technology Centres (SAASTEC) board member. E-mail: puleng.tsie@up.ac.za.

How to cite

Walker, G. J., Bantsi, L., Bukhosini, S., Chikundi, K., Dusrath, A., Kafeero, M., Kamudu Applasawmy, B., Monjero Igadwa, K., Moswetsi, K., Rikhotso, S., Schwartz, M. J. and Tsie, P. (2020). 'Models to build capacity for African science centres and science communication: needs and assets'. JCOM 19 (01), A05. https://doi.org/10.22323/2.19010205. 